\title{
HISTÓRIA, ROMANCE E A “NARRATIVA FILOSÓFICA" NO ILUMINISMO BRITÂNICO
}

History, romance and the "philosophical narrative" in the British Enlightenment História, romance y la "narrativa filosófica" en el Iluminismo britânico

JoÃo de AZEVEdo e Dias DUARTE

http://dx.doi.org/10.1590/\$2178-14942017000300003

João de Azevedo e Dias Duarte é mestre e doutor em História Social pela Pontifícia Universidade Católica do Rio de Janeiro (PUC-Rio) e professor de História Moderna na PUC-Rio (jadduarte@gmail.com).

Artigo recebido em 1 de junho e aprovado para publicação em 30 de agosto de 2017. 


\title{
RESUMO
}

Este artigo articula alguns argumentos relativos à função das narrativas historiográfica e romanesca no século $\mathrm{XVIII}$. Sugere-se que elas compartilhavam alguns elementos-chave - notadamente, um mesmo propósito pedagógico-civilizador e um conjunto de dispositivos retóricos comuns - que conformavam o que se poderia chamar de "narrativa filosófica". Seguindo essa premissa, toma-se o "iluminismo britânico" - entendido como um programa político-social letrado, matriz para a produção e a circulação de textos de caráter historiográfico, ensaístico e romanesco no século XVIII - como base para um exame do contexto letrado setecentista e de textos de autores contemporâneos como David Hume e Henry Fielding.

Palavras-CHAVE: História; romance; narrativa; iluminismo; David Hume; Henry Fielding.

\begin{abstract}
This article articulates some arguments concerning the function of historiographical and novelistic narratives in the eighteenth century. It suggests that they shared some key elements - namely a pedagogical-civilizing purpose and a set of common rhetorical devices - that shaped what could be called "philosophical narrative". Following this assumption, the "British Enlightenment" - understood as a literary, political and social program and a matrix for the production and circulation of historiographical, essayistic and novelistic texts in the 1700s - is used as a basis for examining the eighteenth century literary context and contemporary authors such as David Hume and Henry Fielding.
\end{abstract}

KeYwords: History; novel; narrative; the Enlightenment; David Hume; Henry Fielding.

\section{RESUMEN}

Este artículo desarrolla algunos argumentos sobre la función de las narraciones historiográficas y novelísticas en el siglo XVIII. Se sugiere que estas compartian algunos elementos-clave - notablemente, un propósito pedagógico-civilizador y un conjunto de dispositivos retóricos comunes - que conformaban lo que podría llamarse "narrativa filosófica". Siguiendo esta premisa, la "Ilustración Británica" - entendida como un programa político-social literario, una matriz para la producción y circulación de textos de carácter historiográfico, ensayístico y novelístico en el siglo XVIII - es utilizada como base para un examen del contexto literario del siglo XVIII y de autores contemporáneos como David Hume y Henry Fielding.

Palabras-Clave: Historia; novella; narrativa; la llustración; David Hume; Henry Fielding. 


\section{HistóRIA, ROMANCE E ILUMINISMO: CONSIDERAÇÕES PRELIMINARES}
A historiografia no século XVIII vem sendo de há muito predominantemente abordada de uma perspectiva disciplinar, preocupada em precisar as origens e traçar o caminho de formação da História como disciplina científica. Pelo menos desde os trabalhos seminais de Arnaldo Momigliano, acostumamo-nos a conceber a chamada "história filosófica iluminista" como um dos três elementos que, junto com a história literária clássico-humanista e as tradições críticas da erudição filológica e antiquária, concorreram para conformar a ciência histórica do século XIX. Se, por um lado, essa abordagem rendeu uma série de excelentes trabalhos que contribuíram para o detalhamento e compreensão desse processo de longo prazo (Nadel, 1964; Momigliano, 2004; Levine, 1987, 1991, 1999), por outro, ela tendeu amiúde a relegar a historiografia do século XVIII à condição de mero momento preliminar, que ora anteciparia ora retardaria a obtenção da maioridade profissional, bem como a obscurecer uma série de questões específicas ligadas à sua qualidade "literária", questões de representação, narrativa, retórica e autoridade textual. ${ }^{1}$

Ao mesmo tempo, o romance foi também frequentemente tratado de forma teleológica por uma história literária que assumia a sua forma oitocentista como modelo, remontando ao século XVIII, e até a passados mais distantes, em busca de suas "origens" e "formação". "Epopeia burguesa", na famosa definição de Hegel, o romance do século XVIII foi amiúde caracterizado como uma forma nova, revolucionária, cujo "realismo" rompia radicalmente com a tradição literária e cultural anterior, refletindo a visão de mundo de uma determinada classe social, a "burguesia", e um projeto de modernidade baseado em "capitalismo", "secularização", "individualismo" e "empirismo". Se, por um lado, tal abordagem rendeu trabalhos importantes, por outro, ao se vincular de forma direta e unilinear o romance a determinada classe social ou projeto revolucionário de modernidade, corre-se o risco de reduzir a complexidade do problema de sua inscrição histórica e sociocultural a uma mera "reflexologia" que ignora os processos complexos e dinâmicos de circulação e de negociação cultural (releituras,

\footnotetext{
${ }^{1}$ Trabalhos recentes, porém, têm evitado esse viés disciplinar por meio de abordagens mais sensíveis às especificidades da historiografia setecentista. Cf. Hicks (1996), O'Brien (1997) e Phillips (2000).
} 
adequações, interpretações etc.) que têm lugar nos textos. ${ }^{2}$ Em particular - e à semelhança do ocorrido no campo dos estudos em historiografia -, ela tendeu, com notáveis exceções, ${ }^{3}$ a converter o século XVIII em momento preliminar e a inibir uma investigação mais cuidadosa das especificidades da prosa de ficção nesse período, em particular sua relativa indefinição e eventuais interseções com outras formas de escrita, incluindo-se formas não ficcionais.

Finalmente, em relação ao "iluminismo", trabalhos recentes, sensíveis a especificidades e matizes regionais e confessionais, têm concorrido para questionar certos estereótipos herdados do século XIX, especialmente no que diz respeito à sua definição como um fenômeno unívoco, sua relação supostamente antitética com a "religião" e sua caracterização como um programa secular, igualitário e democrático de emancipação humana. Representante destacado dessas tendências revisionistas no campo dos estudos sobre o iluminismo, o historiador inglês John Pocock tem, desde a década de 1980, apontado para aspectos "conservadores" e "clericais" reprimidos pelo "paradigma do lluminismo como liberação radical" (1998: 84), bem como para a multiplicidade irredutível dos fenômenos referidos pelo conceito (cf. 1985; 1999). Em suas palavras, "'iluminismo' é uma palavra ou significante e não um fenômeno único e unificável que ele significa de forma consistente" (2008: 83). ${ }^{4}$

Haja vista essas considerações, este artigo procura examinar a relação entre "história", "romance" e "iluminismo" de um modo que seja sensível às maneiras variadas e complexas pelas quais valores, instituições, costumes e práticas eram dinamicamente negociados em textos do século XVIII, evitando tomar categorias como estruturas atemporais ou reduzir enunciados a meras expressões de visões de mundo totalizantes ou de conceitos rígidos. Assim, toma-se como ponto de partida da discussão uma definição precisa de "iluminismo", entendido como um projeto político-social letrado inglês (e, depois do Tratado de União, em 1707, britânico), originalmente articulado, no início do século XVIII, por elites intelectuais e políticas seculares preocupadas em evitar a recorrência das guerras civis religiosas que assolaram o território europeu nos séculos XVI e XVII. Configurando-se como um programa de ação voltado tanto para a redução da capacidade das igrejas e seitas de perturbar a paz civil, desafiando a autoridade secular, quanto para a disciplinarização/civilização dos modos da população, o iluminismo teve alguns efeitos literários significativos, impactando na criação e na reelaboração de formas

\footnotetext{
2 Sobre as noções de "negociação" e de circulação de "energia social", cf. Greenblatt (1988).

${ }^{3}$ Cf. Davis (1983), McKeon (2002 [1987]) e Hunter (1990). Trabalhando na esteira da crítica historicista de lan Watt, esses autores contribuíram, de diferentes maneiras, para refinar as hipóteses de Watt relativas às relações entre estruturas sociais e formas literárias.

${ }^{4}$ Além dos textos referidos de Pocock, remeto o leitor interessado nesse debate aos seguintes trabalhos: Porter \& Teich (1981), Baker \& Reill (2001), Schmidt (2014), Robertson (2005) e Edelstein (2010).
} 
e dispositivos específicos. Entre esses, destaca-se aqui, como objeto deste artigo, a "narrativa filosófica" , forma que, caracterizada por um propósito pedagógico bem definido (incutir um temperamento "filosófico", "civil" ou "polido" em seus leitores) e por um conjunto de dispositivos retóricos particulares (entre os quais se destaca a presença de um narrador/crítico que intervém na ação narrada e orienta a atitude e o juízo do leitor em relação a ela e aos personagens), se desenvolveu paralelamente nos gêneros históricos e no romanesco. Daí a importância de, desrespeitando as fronteiras disciplinares contemporâneas, examinar a imbricação entre esses gêneros no contexto letrado do setecentos britânico, estudando-os conjuntamente.

\section{ILUMINISMO BRITÂNICO}

$\mathrm{N}$ o início do século XVIII, após um longo período de instabilidade político-religiosa, que durara quase todo o século anterior, a Inglaterra dava sinais de ingressar numa era nova e promissora. A ameaça dupla do catolicismo e do absolutismo parecia ter sido definitivamente neutralizada pela Revolução de 1688, que depusera o último dos Stuarts, trazendo em sua esteira uma monarquia "mista", limitada e parlamentar, o fim da perseguição às minorias protestantes não conformistas, e um Estado burocrático-fiscal e militar moderno, que começava a assumir a condição de potência comercial e imperial no cenário europeu e mundial. Entretanto, antigas tensões político-religiosas internas não se haviam dissipado e a animosidade entre os diferentes partidos formados nas últimas décadas continuava elevada, amplificada por uma cultura de debate e contestação bastante articulada e disseminada (Harris, 1993). Uma série de fenômenos relativamente recentes - o crescimento demográfico, a expansão do letramento, a multiplicação da mídia impressa, a urbanização e o surgimento de espaços e estabelecimentos comerciais urbanos de sociabilidade, associados às experiências de politização da guerra civil de meados do século e das crises de autoridade da Restauração - havia contribuído para o surgimento de uma nova entidade social referida como o "público" - um substantivo recente, derivado de um adjetivo mais antigo, que significava "o corpo geral da espécie humana, ou de um estado ou nação; o povo" (Johnson, 1755, v. 2: 1598).

Articulado em torno das recentes instituições urbanas de sociabilidade, como as "coffee-houses", e das publicações impressas a elas associadas, o público não foi saudado pelos literati augustanianos como um fenômeno inequivocamente positivo, uma auspiciosa "esfera pública burguesa", portadora de um processo kantiano de "Esclarecimento" (Habermas, 2014). Ao contrário, foi visto como uma entidade suspeita, perigosa, ligada, por um lado, à trivialidade, ao efêmero, ao gosto insaciável por novidades, "galanterias e modas" (Addison \& Steele, 1965, v. 1: 209 [S, 49] - citado em Cowan, 2004: 349), e, por outro, ao furioso e 
incontrolável "espírito de partido", demasiadamente suscetível ao que Shaftesbury, em sua Letter concerning enthusiasm (1708), chamou de "contágio do entusiasmo" (1999: 9), em referência ao fenômeno descrito por Christopher Hill em seu clássico sobre a revolução de 1640 como "mundo de ponta cabeça". Ou seja, o público era visto pelas elites intelectuais e políticas como uma fonte de instabilidade, um fenômeno social potencialmente disruptivo.

Que o público deveria ser controlado de alguma maneira era um consenso entre as elites de ambos os lados da mais importante polaridade partidária, Tories e Whigs, que divergiam apenas quanto à maneira mais apropriada de fazê-lo. Os Tories, que sonhavam com um retorno da ascendência de que desfrutaram sobre a Coroa na década de 1680, insistiam numa receita bem conhecida para disciplinar a população, que consistia essencialmente na obediência à disciplina ditada pelo clero anglicano e garantida pela espada do príncipe. Na opinião dos Tories, tal como articulada pelo clérigo High-Church Henry Sacheverell, apenas uma aderência estrita aos "princípios da Igreja da Inglaterra" poderia garantir a saúde moral da nação e, por extensão, a segurança do "governo inglês" (1709: 14). Entretanto, perto do final da primeira década do século XVIII, os Whigs divisaram uma alternativa a essa visão, que se provaria muito mais eficiente como instrumento de disciplinarização social. Tratava-se do que críticos recentes chamaram de "whigismo polido", " política da polidez" ou, simplesmente, "iluminismo inglês" (cf. Pocock, 1985, e Klein, 1989, 1993, 1994, 2005). Conservadora, a política da polidez tinha um propósito duplo: afrouxar a autoridade das elites clericais e promover uma reforma da vida pública, que transferisse o ônus do seu controle da vigilância repressiva do Estado e da Igreja para a autovigilância dos indivíduos. Tal propósito envolvia um imenso programa de educação das maneiras, uma verdadeira pedagogia da "civilidade".

Assumindo a liderança desse projeto, autores whigs como Anthony Ashley Cooper, o terceiro conde de Shaftesbury, Joseph Addison e Richard Steele, em publicações como Characteristics of men, manners, opinions, times (1711) e The Spectator (1711-1712; 1714), adotaram a persona autoral de moralistas e pedagogos que vinham trazer "a filosofia para fora das celas e das bibliotecas, escolas e faculdades, para morar em clubes e assembleias, em mesas de chá e em cafés" (Addison \& Steele, 1965, v.1: 44 [S,10]). A intenção de retirar a filosofia das "faculdades e celas", onde "nós a muramos, pobre Senhora" (Shaftesbury, 1999: 232), tinha por objetivo, em primeiro lugar, disputar a ascendência intelectual do anglicanismo High-Church, firmemente estabelecida nas instituições de saber tradicionais, a igreja e a universidade. Mas não só. Como se disse, estava em jogo um projeto civilizatório mais amplo, que se depreende diretamente do sentido do termo "filosofia" aqui mobilizado.

Para esses moralistas whigs, a "filosofia" era menos um corpo de pensamento sistemático do que certo temperamento, atitude ou modo de vida chamado "filosófico", " civil" ou 
"polido", e caracterizado pela interiorização de uma ética social calcada em qualidades como "moderação", "autocontrole" e "jovialidade". A filosofia, enquanto ethos, estava associada à arte da "conversação civil", uma arte exercida no comércio do "mundo", e que implicava uma disciplina de observação e distanciamento relativo das paixões e opiniões, próprias e alheias, com o propósito de adequação do comportamento à sensibilidade da companhia. ${ }^{5} 0$ oposto desse temperamento filosófico era um temperamento dito "melancólico", dado a excessos apaixonados, sobretudo de ordem religiosa, como o "entusiasmo" e a "superstição", cujos sintomas eram, entre outros, descontrole corporal e verbal, partidarismo furioso, desrespeito a convenções sociais, acrimônia, insolência e, amiúde, licenciosidade e sedição. Trazer a filosofia para o mundo, segundo essa visão, implicava, portanto, difundir um temperamento "filosófico" entre o "público". Em uma palavra: civilizá-lo.

A realização desse propósito dependia fundamentalmente de encontrar uma forma discursiva retoricamente adequada para "ensinar maneiras e bom senso" ao público (Shaftesbury, 1999: 71). 0 êxito de Characteristics e The Spectator deveu-se, em grande medida, à elaboração e à mobilização eficaz, na forma do "ensaísmo polido", de um conjunto de dispositivos discursivos específicos - mais tarde incorporados pela historiografia e pelo romance -, quais sejam: emulação da viva voce da linguagem coloquial, "natural", pouco ornada; temática familiar e contemporânea; mobilização do sentimento vicário do leitor pela identificação com as personagens; multiplicidade de personagens e vozes, entre os quais se destacava uma persona autoral descoberta e participante. ${ }^{6}$ Esse autor-narrador é descrito em The Spectator como um "espectador da espécie humana", ou seja, alguém cujo distanciamento irônico em relação à vida permitir-lhe-ia "discernir os erros na economia, negócios e diversão dos outros, melhor do que aqueles que neles estão envolvidos" [S,1]. Admirador de The Spectator, Adam Smith, em sua Teoria dos sentimentos morais (1759), desenvolveria as implicações filosófico-morais dessa perspectiva literária ao teorizá-la como a posição ideal para o ajuizamento ético, a posição de um "espectador imparcial".

Configurou-se, assim, em inícios do século XVIII, gestado por elites sociais-intelectuais, um amplo programa político-letrado que serviu de matriz para a produção e circulação de textos de caráter historiográfico, ensaístico e romanesco. No que se segue, busca-se examinar

\footnotetext{
${ }^{5}$ Sobre a arte da "conversação civil" - codificada em uma vasta literatura produzida na Itália e na França nos séculos XVI e XVII a partir do tratado homônimo de Stefano Guazzo (La Civile Conversazione, 1574, traduzido para o inglês em 1581 e 1586 como Civile Conversation) - e sua relação com a cultura da civilidade na Inglaterra e na Europa moderna, cf. Lievsay (1961), Burke (1995), Bryson (1998) e Craveri (2005).

${ }^{6}$ Sobre a forma do ensaio polido na Inglaterra do início do século XVIII e sua relação com a cultura da polidez, cf. Klein (1994) e Duarte (2017).
} 
alguns de seus efeitos nos gêneros históricos e romanesco em meados do século XVIII, com destaque para a produção do que se poderia chamar "narrativa filosófica". Para tanto, toma-se como objetos de análise a produção historiográfica e romanesca de dois letrados setecentistas, David Hume e Henry Fielding, escritores contemporâneos, notáveis tanto por sua autoconsciência retórica e acume teórico quanto por seu envolvimento com a política e a poética da polidez. Antes de vir a eles, porém, é necessário tecer algumas considerações sobre as especificidades do contexto letrado setecentista em relação à história e ao romance. Haja vista o enorme dinamismo e popularidade desses gêneros narrativos em prosa nesse período (cf. O'Brien, 2001; Hunter, 1990) - uma nova era de "prosa" e "comércio", como Adam Smith caracterizou o seu presente (2008: 298-9) -, é razoável supor que sejam um campo privilegiado para examinar a inter-relação entre as dimensões literária e político-sociais desse programa iluminista.

\section{História E ROMANCE NO SÉCUlO XVIII}

$\mathrm{N}$ ão se cogita aqui colapsar a distinção entre "história" e "ficção", embora seja necessário notar que essa distinção funcionava de modo diferente no interior do regime poético-retórico que ainda vigorava no século XVIII, não sendo tão marcada quanto veio a se tornar depois que a ascendência da sensibilidade romântico-positivista oitocentista submeteu as questões relativas à história ao domínio da epistemologia, ao mesmo tempo que converteu a ficção em sinônimo de "literatura" (Gossman, 1978). Até o final do século XVIII, quando a "literatura" não era senão uma prática de escrita e a história uma de suas modalidades, havia certa porosidade entre os gêneros históricos e os gêneros ficcionais. Essa relativa indeterminação dos limites da representação, do verdadeiro e do verossímil, foi aguçada pela "ascensão do romance" realista no século XVIII (Watt, 2010). Não apenas o romance não possuía uma tradição preceptiva e, portanto, convenções poético-retóricas de produção e consumo claramente definidas, como também, e mais do que qualquer outra das formas letradas consagradas, buscava, por meio da exclusão de material lendário e fabuloso e da descrição vívida de cenas ricas em elementos sensoriais e pormenores da vida cotidiana, produzir no leitor um efeito de presença real, semelhante àquele buscado pela historiografia.

Deve-se notar que o "romance" era então um gênero ainda em busca de uma forma e, até mesmo, de um nome. Como é consabido, apenas no final do século XVIII o termo novel (o equivalente em inglês ao nosso "romance") - originalmente um termo de opróbrio, dirigido a produções de apelo popular consideradas de baixa qualidade literária e moral - se firmou como designativo preferencial da nova espécie literária. Até então, "romance" disputava a 
primazia com termos como "estória romanesca" (romance), "epopeia", "vida", "história", entre outros. A confusão de nomes é, em si mesma, sintoma de uma abertura, ou inacabamento, que, segundo Mikhail Bakhtin (1988), é essencial à forma romanesca. Em contraste com os gêneros já estabelecidos, o romance seria dotado de uma capacidade única para assumir, mais que os nomes, também e principalmente, os elementos discursivos (convenções, modos, estratégias e dispositivos) de outros tipos de escrita, integrando-os em sua tessitura particular. Embora, como bem notou Sandra Vasconcelos, "esse modo de ser proteico" não nos autorize a "atribuir indiscriminadamente a todo e qualquer tipo de narrativa a definição de romance" (2007: 18), ele, certamente, complica a tarefa de definição, especialmente nesse contexto fluido das letras na Inglaterra de meados do século XVIII. Assim, em vez de arriscar uma definição ou mesmo uma "working description" do romance setecentista (cf. Hunter, 1990: 23-24), gostaria, ao contrário, de insistir na relativa imprecisão das fronteiras entre história e romance vigente no período, anterior à cisão da matriz discursiva news/nove/s. ${ }^{7}$

Com efeito, uma peculiaridade que chama a atenção de qualquer leitor moderno de romances ingleses do século XVIII é a regularidade com que a palavra "história" é usada como autodescrição, não apenas nos títulos - p.ex.: A história de Joseph Andrews; A história de Tom Jones; Clarissa, ou a história de uma jovem dama; A história de Sir Charles Grandison etc. -, como também nos prefácios, nos quais é amiúde dito que aquilo que se apresenta ao leitor é uma "história verdadeira", " autêntica", baseada na "verdade e na natureza" ou "uma história fiel de fatos", sem "qualquer aparência de ficção", diretamente testemunhada ou editada a partir de relatos de terceiros ou de manuscritos encontrados (Defoe, 2011 [1719]: prefácio; Richardson, 2008 [1740]: prefácio do editor; Fielding, 2011 [1742]: prefácio); que, enquanto tal, "não deve ser considerada como um mero divertimento, um romance (novel) leve ou estória romanesca (romance) passageira, mas como uma história de vida e de maneiras [...] cuja intenção é inculcar as mais elevadas e importantes doutrinas" (Richardson apud Hunter, 1990: 403, n.5). Naturalmente, declarações como essas devem ser tomadas com um grão de sal. Não obstante, acredito que não devam ser simplesmente descartadas como mera manobra diversionista da parte de escritores dispostos a burlar um suposto "controle do imaginário" incidente sobre a produção ficcional na cultura ocidental (Costa Lima, 2009). Embora, sendo a história um gênero prestigioso, fosse natural que "novidades" literárias, sem qualquer tradição bem definida, buscassem amparo sob o venerável nome "história" , há mais nas pretensões de verdade histórica do romance do que mero diversionismo.

\footnotetext{
7 "The history of that process of defining fact and fiction in a cultural sense is also the history of the splitting of the undifferentiated matrix of news/novels into novels on the one hand, and journalism and history on the other" (Davis, 1983: 71).
} 
Esse ponto leva-nos à importante questão da função discursiva do romance e da história. Com efeito, não era simplesmente a capacidade de reproduzir tal e qual uma realidade anterior, a estrita concordância empírico-factual, que o romance visava quando assumia para si o caráter de narrativa histórica verdadeira, do mesmo modo que tampouco era esse o fim último da historiografia tradicional. Ambos aspiravam, em última instância, à condição de portadores de ensinamentos pragmáticos. Ou seja, sua função mimética ou representacional estava subordinada à sua função pedagógica como guia ou "mestra da vida". Assim, mais importante do que reproduzir algo realmente acontecido era transmitir lições úteis, movendo o leitor à imitação de exemplos de virtude, ou à evitação de contraexemplos viciosos, por meio do deleite proporcionado pela leitura de uma narrativa bem construída; ou, como coloca Samuel Richardson no prefácio de Pamela, parafraseando a poética de Horácio: "divertir e entreter, e ao mesmo tempo instruir".

Não surpreende, portanto, que a linguagem dos prefácios das narrativas romanescas seja tão semelhante àquela da preceptiva historiográfica. Numa passagem que bem poderia ter sido extraída de algum dos muitos Artes Historicae disponíveis, ${ }^{8}$ o prefaciador de Robinson Crusoé afirma narrar sua história "com modéstia, com seriedade e uma aplicação religiosa dos acontecimentos aos usos que os sábios sempre thes dão, a saber: a instrução de outros à luz desse exemplo". Alegando ser também, segundo o antigo topos, "filosofia [moral] ensinando através de exemplos" (Bolingbroke, 1844 [1735]: 191), o romance se apresentava como um instrumento de edificação moral semelhante à história convencional - ou, em certos casos, até melhor que ela.

Naturalmente, como deixavam claro os Artes Historicae humanistas, a boa e "digna" história formal era aquela que se ocupava de assuntos de importância pública, político-militares sobretudo, dirigindo suas lições de virtude e prudência a um público masculino e de elite, aqueles gentis-homens destinados a tomar parte nos negotia da vita activa. Em contraste, o romance sempre foi caracterizado por suas tendências demóticas e não "literárias", associadas ao seu foco no presente transitório, nas minúcias da vida privada e cotidiana de personagens comuns, de baixa extração social, e nos movimentos abscônditos da consciência e do "coração". Não obstante, trabalhos recentes têm concorrido para matizar essa distinção, insistindo que os mesmos fenômenos culturais que teriam sido responsáveis pela "ascensão do romance", na Inglaterra do século XVIII, teriam impactado a historiografia de maneira similar.

\footnotetext{
${ }^{8}$ Manuais para a escrita e leitura da história que circulavam entre o público letrado europeu desde o século XVI. Sobre esse gênero de preceptiva, em geral, cf. Grafton (2007). Sobre sua carreira inglesa, em particular, cf. Nadel (1964) e Levine (1991, cap. 9).
} 
Longe de ser um gênero monolítico, a história setecentista, como mostrou Mark Salber Phillips (2000), era uma literatura dinâmica, envolvida na adaptação de protocolos herdados da tradição preceptiva. Sem deixar de insistir nos velhos topoi acerca da "dignidade da história", a história, ou melhor, o conjunto diversificado de "gêneros de escrita histórica", encontrava-se, em meados do século XVIII, em meio a um amplo e complexo processo de "reenquadramento" (reframing) da concepção subjacente do seu objeto mimético, de seus modos de representação e de suas ferramentas de análise em função dos interesses de uma inédita cultura comercial moderna. Dirigindo-se a uma audiência muito mais ampla e diversificada do que aquela suposta pelas Artes Historicae humanistas - uma audiência que a história, até certo ponto, compartilhava (e disputava) com o romance -, historiadores começaram a dar mais atenção às dimensões "social", "privada" e "sentimental" da vida no passado. Com a inclusão cada vez mais frequente de tópicos relativos à "linguagem", às "artes", às "ciências", à "religião", às "finanças e administração do governo", aos "costumes" e às "maneiras" etc, ampliou-se significativamente o escopo da experiência humana abarcado pela narrativa histórica. Como sintetiza Karen O'Brien, "a sociedade, em vez da esfera política, tornou-se o objeto principal da investigação histórica, refletindo e instigando mudanças na composição do público leitor de trabalhos históricos" (2001: 109).

A grande história política, clássico-humanista, era então absorvida pela categoria mais ampla de uma "história civil", ou da "civilização", e essa transformação impunha dificuldades inéditas no âmbito da representação histórica. Como coloca Reinhart Koselleck, a emergência de uma concepção da história como um "singular coletivo" fez com que se passasse "a exigir da história uma maior capacidade de representação, de modo que se mostrasse capaz de trazer à luz - em lugar de sequências cronológicas - os motivos que permaneciam ocultos, criando assim um complexo pragmático, a fim de extrair do acontecimento casual uma ordem interna" (2006: 51). Ou seja, à medida que a história deixava de ser concebida como o relato de um acontecimento particular (a história da batalha de x ou y, p.ex.), passando a ser vista como uma macro-narrativa explicativa da dinâmica temporal da "civilização", a distinção clássica entre história e poesia, estabelecida por Aristóteles no capítulo 9 da Poética, tornava-se problemática. Deixando de se limitar ao particular - "o que fez Alcibíades ou o que Ihe aconteceu" (Aristóteles, 2008: 54 [1451b10-12]) -, a história passava a reivindicar também o caráter filosófico e universal que Aristóteles havia concedido à poesia (i. e., à ficção), complicando a distinção discursiva.

Em suma, no contexto letrado da Inglaterra do século XVIII, narrativa histórica e narrativa romanesca, competindo por uma audiência semelhante, aproximavam-se de várias maneiras, compartilhando elementos formais, temáticos e funcionais. Explorar essas interseções, 
desrespeitando nossas fronteiras disciplinares e genéricas, permite abordar questões pertinentes tanto à história da historiografia quanto à história do romance modernos, questões relativas à retórica e à construção da autoridade discursiva, aos limites da representação (do verdadeiro e do verossímil) e aos parâmetros ético-políticos e epistêmicos das narrativas histórica e romanesca no século XVIII. À guisa de conclusão e com o propósito de apenas apontar alguns caminhos para um posterior aprofundamento analítico, procurar-se-á mostrar de que modo as questões levantadas até aqui são articuladas em algumas obras de David Hume e de Henry Fielding.

\section{David Hume e Henry Fielding}

$\mathrm{O}$ prestígio de que David Hume desfruta hoje, e lhe garante uma posição de destaque no seleto panteão filosófico, é inseparável de seu primeiro e mais ambicioso livro, o Tratado sobre a natureza humana (1739). No entanto, a fama que Hume angariou em vida deveu-se não ao Tratado, livro pouquíssimo lido por seus contemporâneos, mas sim aos seus ensaios e, sobretudo, à sua História da Inglaterra, obra publicada em seis volumes entre 1754 e 1762. Foi o fracasso do Tratado que o levou à mudança de foco, do geral ao particular, e de modo de escrita, da filosofia sistemática, ou "metafísica", ao ensaísmo e à historiografia. Ao fazer essa transição, Hume estava conscientemente adaptando-se a um mercado literário em franca expansão e aos gostos de um público "polido"; um público em grande parte urbano, de classe média e feminino, já acostumado à leitura de periódicos morais como The Spectator, e cada vez mais adepto do novo gênero do "romance".

Hume sabia estar disputando essa audiência com o romance. Seu ensaio de 1741, "Do estudo da história", tem por objetivo explícito convencer suas leitoras de que a leitura de livros de história é ao mesmo tempo mais instrutiva e agradável do que a leitura de "romances e estórias romanescas" (2004: 781 [E III.VI.1]). Ao passo que esse último tipo de composição ofereceria, na opinião de Hume, apenas "falsas representações da espécie humana", a história, ao contrário, seria a melhor maneira de nos tornarmos "familiarizados com os assuntos humanos, sem nada diminuir dos mais delicados sentimentos de virtude" (2004: 785-786 [E III.VI.7]). 0 principal argumento oferecido por Hume para justificar a superioridade ético-cognitiva da história estava diretamente relacionado ao tipo de perspectiva privilegiada que ela ofereceria sobre os assuntos humanos. 0 ponto de vista da história seria uma mediania entre dois extremos: a visão do "man of business", i.e., aquele que está diretamente envolvido "na vida e na ação" e que, portanto, tende a perceber os caracteres alheios apenas pelo viés do seu interesse particular e a julgá-los segundo a "violência de sua paixão"; e a visão do "filósofo" que, observando "os caracteres e as maneiras" dos homens da distância do seu gabinete, encontra-se longe demais para se deixar 
afetar na medida certa para julgá-los corretamente, ou seja, para "sentir a diferença entre vício e virtude". Entre esses dois polos, situam-se "os escritores de história", que, "assim como os seus leitores, estão suficientemente interessados nos caracteres e eventos para entreter um sentimento vivaz de censura ou aprovação, e, ao mesmo tempo, não possuem qualquer preocupação ou interesse particular que perverta o seu julgamento" (2004: 785-786 [E III.VI.7]).

É precisamente esse equilíbrio entre distanciamento irônico e proximidade sentimental que Hume busca cultivar em sua prática historiográfica. Sua História da Inglaterra narra os acontecimentos não da perspectiva de alguém que teve uma participação ativa no passado político recente e busca transmitir aos seus pares lições sobre como agir nos negócios públicos - como era comum na historiografia clássica e humanista -, mas sim daquela de um espectador inteligente que tenta dar unidade a um conjunto vasto de experiências passadas, articulando-as entre elas próprias e ao presente, sem perder de vista o detalhe, oferecendo ao seu leitor (também ele um espectador) um quadro no qual são visíveis tanto o desenho geral quanto o colorido particular. Não à toa, a "imparcialidade" era a qualidade da qual Hume mais se vangloriava como historiador, aquela que o separava de seus predecessores tories e whigs, a quem faltavam "estilo, julgamento, imparcialidade e cuidado" (Letters 1:170 apud Wootton, 2009: 449). Imparcialidade, para Hume, significava sobretudo "desinteresse", ou a capacidade de se colocar acima dos partidos, pois era o faccionalismo que impedia seus contemporâneos de chegar a um juízo equilibrado acerca do passado e, sobretudo, de quanto este se distinguia do presente. Ao passo que historiadores whigs e tories enfatizavam uma suposta continuidade constitucional e davam pouca atenção à mudança social, Hume insistia na distância que os separava dos seus antepassados. Hume acreditava que a sociedade comercial da Inglaterra hanoveriana desfrutava de uma ordem constitucional cujas liberdades eram mais amplas e sistemáticas do que jamais fora o caso no passado. Porém "o mais completo sistema de liberdade jamais conhecido pela humanidade" (1983: 531 [HE 71:70, v6]) não foi o resultado do trabalho de um único partido, mas sim a "consequência não intencionada" de uma miríade de causas cegas. A história é um processo prenhe de ironia, e apenas um espectador desinteressado, "filosófico", é capaz de apreciá-la adequadamente. Mas o distanciamento e o equilíbrio não eram suficientes. Uma narrativa bem-sucedida deveria ser capaz de cultivar uma variedade de maneiras de se relacionar com o passado, estimulando também a "simpatia" do espectador, i.e., a sensibilidade do leitor pelo drama individual das personagens, tanto quanto o distanciamento filosófico; a atualidade e a vivacidade tanto quanto a ironia. Daí o cuidado minucioso com que personagens como o monarca Stuart Carlos I são representados no texto.

Henry Fielding também tentou a sorte no emergente mercado literário inglês ao mesmo tempo que Hume. Porém, ao contrário do filósofo escocês, vinha não de uma malfadada 
empreitada filosófica, e sim de uma carreira bem-sucedida como dramaturgo, interrompida bruscamente pela Lei de Licenciamento de 1737, que submeteu os teatros à censura do Estado e o deixou na penúria. Em vez de enveredar pela história formal, como Hume, Fielding optou pelo que chamou de "nova província do escrever", i.e., a prosa narrativa de ficção, na qual autores como Daniel Defoe e Samuel Richardson granjearam grande popularidade. Porém, preocupado em conferir dignidade e credibilidade a suas produções, Fielding, assim como outros romancistas contemporâneos, evitou referir-se a elas como "romances" ou "estórias romanescas", preferindo termos consagrados pela tradição clássica como "epopeia", "biografia" e "história". O que é notável a respeito de Fielding é que ele não apenas alegou oferecer "histórias verdadeiras" como também produziu um conjunto de argumentos teóricos em defesa da historicidade do novo formato narrativo por ele praticado.

Para Fielding, livros como Dom Quixote, Joseph Andrews ou Tom Jones seriam mais confiáveis e instrutivos do que histórias convencionais, demasiado presas à contingência e a vieses partidários. Ao passo que historiadores como Lord Clarendon, Whitelock, Paul de Rapin e todos aqueles outros "escritores romanescos que intitulam seus livros 'a história da Inglaterra, a história da França, da Espanha etc." (2008a: 162; 2011: 229) seriam credíveis apenas no que diz respeito a suas descrições de lugares, "conosco, biógrafos, o caso é diferente: os fatos que apresentamos são confiáveis, embora amiúde erremos a época e o país em que ocorreram" (2008a: 162; 2011: 230). Assim, pergunta-se Fielding, "não será um livro como o que registra os feitos do renomado Dom Quixote mais digno do nome de história do que até mesmo o [da célebre Historiae de Rebus Hispaniae, de Juan] de Mariana? Pois ao passo que o último se confina a um período específico de tempo e a uma nação específica, o primeiro é a história do mundo em geral, pelo menos daquela parte polida por leis, artes e ciências, e isso desde o momento em que foi primeiramente polida até os dias de hoje; e também doravante, por quanto tempo ela assim perdurar" (2008a: 163-164; 2011: 231 - grifos meus).

Invertendo 0 argumento de Hume, Fielding defende a superioridade da forma romanesca sobre outros tipos de composição, inclusive a história convencional, atribuindo-a à perspectiva privilegiada que ela é capaz de oferecer sobre o mundo (a visão de espectadores situados nos "bastidores") e ao tipo de juízo moral mais equilibrado e justo que dela decorreria. Assim como a história convencional, a "história verdadeira" apresentaria ações e caracteres particulares (conquanto imaginários); no entanto, oferecê-los-ia não na mera sucessão cronológica, na (des)ordem da causalidade, e sim organizados artisticamente em um todo unificado, uma estrutura de enredo dotada de uma coerência extraordinária. De fato, a ordem e simetria notáveis do complexo enredo dos romances de Fielding é algo frequentemente apontado pelos seus comentadores, desde seus primeiros críticos ainda no século XVIII (cf. Bender, in Fielding, 
2008b: xxix-xxxii; e Watt, 2010: 287). A peça central dessa imensa estrutura, o eixo que garante o seu movimento harmônico, articulando cada uma de suas partes à sua catástrofe final é o próprio narrador. Com suas frequentes interrupções, apartes, comentários, digressões, 0 narrador mantém o controle da história e orienta o leitor em relação a ela, convocando-o também a ocupar a posição privilegiada que é a sua - "e nenhum escritor que não tenha esse privilégio deveria escrever mais que dicionários e cartilhas" (Fielding, 1971: 193; 2008b: 285) -: "a posição dos bastidores", de onde é possível avaliar vantajosamente a ação e os caracteres. 0 romance fieldingiano oferecia ao leitor essa perspectiva, a meia distância do palco/ mundo, algo que a história tradicional, por sua limitação à contingência, seria incapaz de fazer.

Esta breve análise de Hume e Fielding sugere a existência de uma competição genérica entre a historiografia, em pleno processo de reconfiguração de seus parâmetros discursivos, e o romance, em processo de afirmação literária. Ambas as formas, tal como concebidas por esses autores, buscavam se oferecer como alternativas mais eficazes do que a outra, não no que diz respeito à sua capacidade de restituir uma suposta objetividade do real, mas sim em sua função pragmática de orientação ética. Em ambos os casos, a historicidade e o estatuto de verdade reclamados pela narrativa não dependiam da produção de uma ilusão de realidade que demandasse a supressão da voz narrativa. Muito pelo contrário, a "tagarelice" da voz narrativa, manifesta através de artifícios como a digressão, o parêntese, e o aparte - que tanto ofenderão o decoro discursivo do romancista e do historiador oitocentistas - é aqui parte substancial da eficácia retórica dessas narrativas como elemento-chave do ethos "filosófico" do narrador que não pretendia, à maneira de um Leopold von Ranke, simplesmente expor a realidade "wie es eigentlich gewesen" (como de fato ocorreu), mas sim apresentar ao leitor, por meio de uma forma artística, padrões excepcionalmente inteligíveis de experiência humana que o ajudassem a exercitar seu juízo crítico e, consequentemente, a bem se conduzir na vida. Ao ler narrativas como a História da Inglaterra, de Hume, Joseph Andrews e Tom Jones, de Fielding, o leitor, supunham seus autores, habituar-se-ia a assumir na vida uma perspectiva equilibrada entre proximidade empática e distanciamento crítico, assumindo assim o caráter filosófico do "homem de franqueza e verdadeiro entendimento" (the man of candour and true understanding), que "nunca se apressa em condenar" (Fielding, 1971: 193; 2008b: 286).

\section{REFERÊNCIAS BIBLIOGRÁFICAS}

ADDISON, Joseph \& STEELE, Richard. The Spectator. Donald Frederic Bond (ed.). 5 vols. Oxford: Clarendon Press, 1965.

ARISTÓTELES. Poética. Maria Helena da Rocha Pereira (ed.). Trad. Ana Maria Valente. 3ạ ed. Lisboa: Fundação Calouste Gulbenkian, 2008. 
BAKER, Keith \& REILL, Peter (orgs.). What's left of Enlightenment?: a postmodern question. Stanford: Stanford University Press, 2001.

BAKHTIN, Mikhail. Epos e romance. In: Questões de literatura e de estética. A teoria do romance. São Paulo: Hucitec-Unesp, 1988.

BENDER, John. Introduction. In: FIELDING, Henry. Tom Jones. John B. Bender e Simon Stern (eds). Oxford: Oxford University Press, 2008b.

BOLINGBROKE, Henry St. John. Letters on the study and use of History. In: The works of Lord Bolingbroke, II: 173-334. London: Henry G. Bohn, 1844. Disponível em: http://www.indiana.edu/ enltnmt/texts/ Bolingbroke.html. Acesso em: 20/03/2017.

BRYSON, Anna. From courtesy to civility: changing codes of conduct in early modern England. Oxford/New York: Clarendon Press/Oxford University Press, 1998.

BURKE, Peter. A arte da conversação. Trad. Alvaro Hattnher. São Paulo: Editora Unesp, 1995.

COSTA LIMA, Luiz. O controle do imaginário e a afirmação do romance: Dom Quixote, As relações perigosas, Moll Flanders, Tristam Shandy. São Paulo: Companhia das Letras, 2009.

COWAN, Brian. Mr. Spectator and the Coffeehouse Public Sphere. Eighteenth-Century Studies, v. 37, n. 3, p. 345-66, 1 Abr. 2004.

CRAVERI, Benedetta. The age of conversation. New York: New York Review Books, 2005.

DAVIS, Lennard J. Factual fictions: the origins of the English novel. New York: Columbia University Press, 1983.

DEFOE, Daniel. Robinson Crusoé. Trad. Sergio Flaksman. São Paulo: Penguin Classics Companhia das Letras, 2011.

DUARTE, João. O progresso do peregrino: religião e política na gênese do lluminismo inglês. Curitiba: Editora Prismas, 2017.

EDELSTEIN, Dan. The Enlightenment: a genealogy. Chicago: University of Chicago Press, 2010.

FIELDING, Henry. Tom Jones. Trad. Octavio Mendes Cajado. São Paulo: Abril Cultural, 1971.

Joseph Andrews and Shamela. Douglas Brooks-Davis e Thomas Keymer (eds.). Oxford: Oxford University Press, 2008a.

Tom Jones. John B. Bender e Simon Stern (eds). Oxford: Oxford University Press, 2008b.

A história das aventuras de Joseph Andrews e seu amigo o Senhor Abraham Adams. Trad. Roger Maioli dos Santos. Cotia/Campinas: Ateliê Editorial/Editora da Unicamp, 2011.

GOSSMAN, Lionel. History and literature. Reproduction or signification. In: CANARY, Robert \& KOZICKI, Henry (eds.). The writing of History: literary form and historical understanding. Madison: University of Wisconsin Press, 1978.

GRAFTON, Anthony. What was History?: The art of History in early modern Europe. Cambridge: Cambridge University Press, 2007.

GREENBLATT, Stephen Jay. Shakespearean negotiations: the circulation of social energy in Renaissance England. Berkeley: University of California Press, 1988. 
HABERMAS, Jürgen. Mudança estrutural da esfera pública: investigações sobre uma categoria da sociedade burguesa. Trad. Denílson Luís Werle. São Paulo: Editora Unesp, 2014.

HARRIS, Tim. Politics under the later Stuarts: party conflict in a divided society, 1660-1715. London/New York: Longman, 1993.

HICKS, Philip. Neoclassical History and English culture: from Clarendon to Hume. Basingstoke: Macmillan Press; New York: St. Martin's Press, 1996.

HUME, David. The History of England from the invasion of Julius Caesar to the Revolution in 1688. William B. Todd (ed.). Indianapolis: Liberty Fund, 1983, 6 v.

. Ensaios morais, políticos e literários. Eugene F. Miller (ed.). Trad. Luciano Trigo. Rio de Janeiro: Topbooks, 2004.

HUNTER, J. Paul. Before novels: the cultural contexts of eighteenth-century English fiction. New York: Norton, 1990.

JOHNSON, Samuel. A Dictionary of the English Language. London, 1755, 2 v.

KLEIN, Lawrence Eliot. Liberty, manners and politeness in early eighteenth-century England. Historical Journal, v. 32, n. 3, p. 583-605, 1989.

Shaftesbury, politeness and the politics of religion. In: SKINNER, Quentin \& PHILLIPSON, Nicholas (orgs.). Political discourse in early modern Britain. Cambridge/New York: Cambridge University Press, 1993, p. 283-301.

Shaftesbury and the culture of politeness: moral discourse and cultural politics in early eighteenth-century England. Cambridge/New York: Cambridge University Press, 1994.

Joseph Addison's Whiggism. In: WOMERSLEY, David (org.). "Cultures of Whiggism": new essays on English literature and culture in the long eighteenth-century. Newark: University of Delaware Press, 2005.

KOSELLECK, Reinhart. Futuro passado. Trad. Wilma Patrícia Maas e Carlos Almeida Pereira. Rio de Janeiro: Ed. PUC-Rio/Contraponto, 2006.

LEVINE, Joseph. Humanism and History: origins of modern English Historiography. Ithaca: Cornell University Press, 1987. 1991.

The battle of the books: History and Literature in the Augustan Age. Ithaca: Cornell University Press,

The autonomy of History: truth and method from Erasmus to Gibbon. Chicago: University of Chicago Press, 1999.

LIEVSAY, John Leon. Stefano Guazzo and the English Renaissance, 1575-1675. Chapel Hill: University of North Carolina Press, 1961.

MCKEON, Michael. The origins of the English novel, 1600-1740. Baltimore: John Hopkins University Press, 2002.

MOMIGLIANO, Arnaldo. As raízes clássicas da historiografia moderna. Trad. Maria Beatriz Borba Florenzano. Bauru: EDUSC, 2004.

NADEL, George H. Philosophy of History before Historicism. History and Theory, v. 3, n. 3, p. 291-315, 1 jan. 1964. 
O'BRIEN, Karen. Narratives of Enlightenment: cosmopolitan History from Voltaire to Gibbon. Cambridge: Cambridge University Press, 1997.

. The History market in eighteenth-century England. In: RIVERS, Isabel (ed.) Books and their readers in eighteenth-century England: new essays. Leicester: Leicester University Press, 2001, p. 105-33.

PHILLIPS, Mark. Society and sentiment: genres of historical writing in Britain, 1740-1820. Princeton: Princeton University Press, 2000.

POCOCK, J. G. A. Clergy and commerce: the conservative Enlightenment in England. In: L'Età dei Lumi: studi storici sur Settecento Europeo in onore di Franco Venturi, v. 1, p. 525-62. Napoli: Jovene Editore, 1985.

Conservative Enlightenment and democratic revolutions: the American and French cases in British perspective. Government and Opposition: a Journal of Comparative Politics, v. 24, n. 1, p. 81-105, inverno 1998.

_ Barbarism and religion: narratives of civil government. v. 2. Cambridge, U.K./New York: Cambridge University Press, 1999.

- Historiography and Enlightenment: a view of their history. Modern Intellectual History, v. 5, n. 1, 12 mar. 2008.

PORTER, Roy \& TEICH, Mikuláš (eds.). The Enlightenment in national context. Cambridge/New York: Cambridge University Press, 1981.

RICHARDSON, Samuel. Pamela: or virtue rewarded. Ed. Thomas Keymer e Alice Wakely. Oxford/New York: Oxford University Press, 2008.

ROBERTSON, John. The case for the Enlightenment: Scotland and Naples, 1680-1760. Cambridge/New York: Cambridge University Press, 2005.

SACHEVERELL, Henry. The perils of false brethren, both in Church, and State. London, 1709. Disponivel em: http://find.galegroup.com/ecco/infomark.do?\&source=gale\&prodld=ECCO\&userGroupName=capes\&tabID= T001\&docld=CW3304603453\&type=multipage\&contentSet=ECCOArticles\&version=1.0\&docLevel=FASCI MILE. Acesso em: 12/03/2017.

SCHMIDT, James. Enlightenment as concept and context. Journal of the History of Ideas, v. 75, n. 4, p. 677-85, 2014.

SHAFTESBURY, Anthony Ashley Cooper. Characteristics of men, manners, opinions, times. Lawrence Eliot Klein (ed.). Cambridge/New York: Cambridge University Press, 1999.

SMITH, Adam. Conferências sobre retórica \& belas-letras. J. C. Bryce (ed.). Trad. Rebeca Schwartz. Rio de Janeiro: Topbooks, 2008.

VASCONCELOS, Sandra Guardini. A formação do romance inglês: ensaios teóricos. São Paulo: Aderaldo \& Rothschild/FAPESP, 2007.

WATT, Ian. A ascensão do romance. Trad. Hildegard Feist. São Paulo: Companhia das Letras, 2010.

WOOTON, David. David Hume, 'the Historian'. In: The Cambridge companion to Hume. David Fate Norton (ed.). Cambridge/New York: Cambridge University Press, 1993. 